\title{
Revitalização urbana e turismo: o caso do Centro Histórico de Aracaju (Sergipe, Brasil)
}

\section{Urban restoration and tourism: the case of Aracaju Historic Center (Sergipe, Brazil)}

\author{
Rafaelle Camilla dos Santos Pinheiro (PINHEIRO, R. C. dos S.) \\ Cristiane Alcântara de Jesus Santos (SANTOS, C. A. de J.) ${ }^{* *}$
}

\begin{abstract}
RESUMO - O espaço urbano da cidade de Aracaju (Sergipe, Brasil) experimentou um processo de reestruturação em função do crescimento do seu fluxo turístico, em que vários espaços emblemáticos da mesma passaram por um processo de qualificação, a fim de atender a nova função - a turística- a ser desempenhada por ela. Dentre estes espaços, o Centro Histórico se desenvolveu a partir da expansão econômica do estado de Sergipe como cenário das inúmeras reestruturações arquitetônicas acompanhando as transformações na vida social e cultural dos sergipanos. Desta forma, este artigo tem como objetivo analisar as intervenções urbanas realizadas no Centro Histórico de Aracaju, a partir das políticas de turismo desenvolvidas na cidade. Como base metodológica foi realizada pesquisa bibliográfica, visita técnica e pesquisa documental. É importante ressaltar que estes procedimentos foram de fundamental importância para compreender como as transformações urbanísticas aconteceram concomitantemente ao desenvolvimento urbanístico e turístico de Aracaju.
\end{abstract}

Palavras-Chave: Revitalização urbana; Patrimônio Cultural; Centro Histórico de Aracaju; Turismo.

ABSTRACT - Aracaju (Sergipe, Brazil) urban area experienced a restructuring process due to an increase of tourism activity. Several landmark sites went through a qualification process in order to respond to the new touristic function. Among these sites is the Historic Center, which was developed due to the economic expansion of Sergipe, and experienced many architectural restorations reflecting the social and cultural changes of its population. Thus, the purpose of the following article is to evaluate the urban transformation of Aracaju Historic Center based upon the tourism policies developed in Aracaju. Bibliographic research, technical visits and document research were used as methodological basis. It is important to highlight that these procedures were extremely important to comprehend how urban transformation and urban development took place simultaneously.

Key Words: Urban Restoration; Cultural Heritage; Aracaju Historic Center; Tourism.

\footnotetext{
*Acadêmica do Curso de Turismo da Universidade Federal de Sergipe - UFS. Bolsista PAEX (Programa de Extensão) da UFS. Endereço: Av. Marechal Rondon, s./n. - Bloco Departamental I (Bairro: Jardim Rosa Elze). CEP: 49100-000 - São Cristóvão - Sergipe (Brasil). Telefone: (79) 2105-6332 E-mail: pinhorafaelly@gmail.com

** Graduação e Mestrado em Geografia pela UFS. Doutoranda em Geografia junto à Universitat de Barcelona. Professora do Curso de Turismo da UFS. Endereço: Av. Marechal Rondon, s./n. Bloco Departamental I (Bairro: Jardiz Rosa Elze). CEP: 49100-000 - São Cristóvão - Sergipe (Brasil). Telefone: (79) 2105-6332. E-mail: cristie09@uol.com.br
} 


\section{INTRODUÇÃO}

O processo de apropriação dos centros históricos das cidades pelo turismo é decorrente de uma série de valores e imagens concretizadas no imaginário dos viajantes, que por sua vez, representam uma demanda social que busca novas experiências a partir do sentimento de estranhamento decorrente do conhecer o outro.

Para atender esta demanda social, gestores públicos e promotores do turismo desenvolvem medidas relacionadas à readequação e revalorização do patrimônio cultural dos espaços centrais urbanos das cidades de forma a proporcionar o consumo globalizado de espaços eleitos pelas suas singularidades.

É através deste processo de readequação dos espaços centrais pelo/para o turismo que ocorre uma gama de conflitos entre o uso turístico e os demais usos já existentes, uma vez que os centros históricos apresentam profundas transformações funcionais e sociais. Assim, das intervenções empreendidas nestes locais emerge uma, entre outras questões: qual o papel do turismo no processo de valorização da cultura e organização dos equipamentos e serviços nos centros urbanos?

Deste modo, o presente trabalho tem como objetivo analisar as intervenções urbanas realizadas no Centro Histórico de Aracaju, a partir das políticas de turismo desenvolvidas em Aracaju, capital do estado de Sergipe (Brasil). A fim de atingir o objetivo proposto foram adotados como procedimentos metodológicos: a pesquisa bibliográfica sobre temas referentes à relação entre patrimônio cultural e turismo, intervenções urbanas em centros históricos, turistificação do espaço urbano e ao Centro Histórico de Aracaju. Também foi realizada pesquisa de campo através de visita técnica ao centro histórico para a observação da dinâmica social deste espaço. Para a análise do papel do Programa de Desenvolvimento do Turismo no Nordeste (PRODETUR/NE I) no processo de revitalização do Centro Histórico de Aracaju foi realizada a pesquisa documental com consulta de documentos institucionais, sobretudo, do Banco do Nordeste (BNB) e da Secretaria do Estado de Turismo (SETUR - Sergipe). 


\section{A APROPRIAÇÃO DA CULTURA E DO URBANO PELO TURISMO}

A expansão do mercado de consumo do turismo promove a permanente necessidade de criação de novos produtos, sendo o mercado um agente importante no processo de turistificação do espaço (CRUZ, 2002). De acordo com a mesma autora, a gestão dos territórios turísticos se dá pelo processo de consumo dos espaços pelo turismo, entendendo os espaços como "um conjunto indissociável de objetos e de ações, de fixos e de fluxos" (CRUZ, 2002, p. 17).

Este processo chamado de turistificação de lugares é caracterizado pela produção de lugares pelo/para o uso turístico e passa a desempenhar papel fundamental na inserção e/ou reaquecimento de economias em declínio. Assim, é introduzido nos lugares um novo sistema de objetos com a finalidade de adequá-los ao novo sistema de ações advindas da demanda social do turismo (LUCHIARI, 1998).

De acordo com Santos (2010a), a criação de lugares turísticos se fundamenta na personalização de lugares e se caracteriza por uma ordenação de signos e valores impressos às comunidades locais. Com isso, o turismo, como um conjunto de atividades, conduz a percepções de símbolos, normas éticas, regras e valores culturais que são trocados e consumidos tanto pelos turistas e, em alguns casos, pelas comunidades visitadas.

A relação entre turismo e espaço se traduz fundamentalmente na indiscutível capacidade que tem o turismo de (re) organizar o conteúdo dos territórios à sua conveniência, no intuito de se criar as condições para que o mesmo possa ocorrer. Ele tem o espaço como o seu principal objeto de consumo, e assim, atua dinamicamente no processo de (re) produção espacial.

Entretanto, a transformação do território pelo turismo pode encontrar resistências, sendo que, de acordo com Cruz (2002, p. 30), os "sistemas de objetos constituídos, criados por sistemas de ações histórica e socialmente estabelecidos, podem configurar-se como barreiras à expansão da atividade turística". Para a autora o poder público local tem o papel importante na mediação dos conflitos gerados pelo choque entre antigos e novos usos do território.

O turismo promove uma "urbanização turística" que conduz os lugares para a entrada no fluxo de informações, bens e pessoas em âmbito global (LUCHIARI, 1998). 
A urbanização turística visa, então, a adequação das localidades para a demanda de um turismo globalizado que requer uma crescente racionalidade em resposta à competitividade global entre os produtos e destinos turísticos (SÁNCHEZ, 2010; CRUZ, 2002).

Do ponto de vista espacial, a relação entre o turismo e o urbano pode ser empreendida por três situações distintas. Segundo Cruz (2002), o urbano antecede o turismo; a urbanização ocorre simultaneamente ao turismo, ou o turismo antecede a urbanização. A incorporação de espaços urbanos pelo turismo, quando não espontânea, pode ser promovida a partir de políticas e projetos de turismo que os direcionem para uma função turística (CRUZ, 2002).

No tocante ao processo de apropriação do espaço central das cidades pelo turismo, em muitos casos, ocorre posteriormente ao processo de urbanização. De fato, os equipamentos urbanos, de lazer e o patrimônio cultural, construídos, utilizados e imaginados a partir das ações sociais historicamente localizadas, são incorporados aos tours realizados na cidade, devido a sua valorização cultural pelo/para o turismo.

Assim sendo, a valorização dos espaços centrais é decorrente do valor simbólico e econômico gerado a partir dos fluxos de pessoas que se direcionam para destinos turísticos para conhecer o patrimônio cultural edificado das cidades. O patrimônio material representado pelos centros históricos, praças, edifícios e monumentos pode ser constituído por estes como elementos principais ou agregadores de valor na oferta de roteiros turísticos em determinada localidade.

A busca pelo desenvolvimento socioeconômico aliado a necessidade de valorizar, preservar e conservar o patrimônio edificado dos espaços urbanos vem promovendo a (re) adequação destes para fins turísticos, ou seja, a sua turistificação. Tal medida é fundamentada nos benefícios pronunciados e vinculados em discursos políticos positivistas que tratam o turismo como um setor promotor do desenvolvimento das cidades, estados e países. Acerca disto Bertoncello (2010, p. 34) afirma que,

[...] el poder público, en sus múltiples niveles e instancias de actuación, participa en esta incentivación, pues activando las clásicas consignas acerca del turismo como "impulsor del desarrollo", interviene en el fomento de un turismo que parece factible de ser desarrollado en cualquier lugar de destino, y ser la vía, si no para alcanzar el desarrollo, al menos para superar las situaciones de crisis socioeconómicas instaladas en muchos de ellos. (Grifo do autor). 
É a partir da junção entre turismo e cultura que os gestores públicos passam a visualizar o turismo como uma oportunidade de desenvolvimento econômico e social para uma localidade ou região. Entretanto, mesmo que um lugar apresente um "potencial turístico cultural", vale-se de uma organização e planejamento da atividade tanto no que diz respeito aos aspectos materiais como imateriais.

Para que o turismo promova o desenvolvimento de uma dada região, faz-se necessária a adoção de uma série de medidas de (re) estruturação dos destinos no que diz respeito a equipamentos básicos e de apoio, infraestrutura urbana e de turismo, atrativos turísticos, serviços e produtos, envolvimento da comunidade local na atividade em todos os níveis de decisões e operações referentes à atividade.

\section{INTERVENÇÕES NOS CENTROS URBANOS PARA O TURISMO}

Os processos de intervenções urbanas recebem várias denominações, entre elas requalificação e revitalização urbana. Segundo Paes (2010, p. 14) tais conceitos "foram elaborados para dar conta deste processo de que se evidencia como uma mudança formal, funcional e simbólica na produção do espaço urbano". Para a autora, tais processos poderiam ser denominados como refuncionalização, posto que a maioria destes tem como objetivo a (re) inserção de funções nos espaços eleitos.

Para Vargas e Castilho (2009) intervir nos centros históricos pressupõe, não somente uma avaliação do valor histórico e patrimonial, mas também o caráter funcional das áreas em relação à estrutura urbana, levantando-se a necessidade de intervir sustentada na identificação de um processo de deterioração urbana.

Ao se tratar do processo de requalificação urbana tem-se o exemplo da cidade de Barcelona para os Jogos Olímpicos de 1992 que "expressa a intencionalidade de atrair oportunidades e usos de interesse histórico-cultural local" (SOTRATTI, 2010, p. 139). Segundo o mesmo autor, a requalificação resulta na aliança entre o patrimônio e os interesses de consumo e do mercado imobiliário através de uma refuncionalização. De acordo com Paes (2010), a requalificação busca, além da restauração das formas, uma modernização para a manutenção dos valores tradicionais arquitetônicos, funcionais ou culturais. 
O termo revitalização, segundo Sánchez (2010, p. 489) "não parece ser um termo apropriado para aquilo que de fato qualifica os processos atuais [de renovação urbana]". Tal afirmação é justificada pelo fato de que os lugares renovados não estão "mortos", uma vez que há uma dinâmica social de indivíduos que, de uma forma ou de outra, mantém o patrimônio histórico cultural.

Outro termo citado para o processo de intervenção urbana é gentrification ou gentrificação utilizado para definir a substituição ou a elitização dos estratos sociais nas áreas centrais (PAES, 2010). Desta forma, a gentrificação corresponde a um conjunto de ações de intervenção urbanística, em que empreendimentos econômicos elegeriam certos espaços da cidade, a exemplo de espaços centrais, e os transformam em áreas de investimento públicos e privados, o que atualmente refere-se à reabilitação de cenários antigos bem como engloba construções totalmente novas (LEITE, 2004 apud CONCEIÇÃO et al., 2010) $)^{1}$.

Como um dos casos emblemáticos de espaços urbanos gentrificados, a Time Square, antes considerada pelos nova-iorquinos como um lugar perigoso, ocupado por prostitutas, cafetões, drogados e traficantes, após um processo de intervenção urbana de aproximadamente três décadas promovido por um plano que previa reformas em mais de 13 hectares entre a Broadway e a Oitava Avenida, atualmente é um dos atrativos turísticos mais visitados em Manhattan e um dos grandes centros de cultura, lazer e negócios da cidade ${ }^{2}$.

Assim, a gentrificação configura-se como um processo de reestruturação da dinâmica econômica e social de locais considerados desordenados e fora dos padrões de consumo global.

Não obstante o termo utilizado, os processos de intervenção urbana, na busca da transformação dos antigos espaços centrais, exige a readequação destes às suas novas funcionalidades, entre elas a turística. Levando-se em consideração que os centros históricos urbanos são espaços multifuncionais, a adequação destes ao posterior uso turístico gera uma concorrência entre este e os usos já existentes, havendo assim uma

\footnotetext{
1 LEITE, R. P. Contra-usos da Cidade: Lugares e Espaço Público na Experiência Urbana Contemporânea. Campinas / São Cristóvão: UNICAMP / UFS, 2004.

${ }^{2}$ THE NEW YORK TIMES. Após 30 anos, reforma da Times Square será concluída: revitalização de ponto histórico da cidade fez criminalidade diminuir e atraiu empresas e turistas. 10/11/2010. Disponível em: <http://ultimosegundo.ig.com.br/mundo/nyt>. Acesso em: 04/04/2011.
} 
gama de conflitos entre os usos antigos e o uso turístico que se pretende inserir-se no mesmo espaço. Sobre isso, Cruz (2002, p. 17) afirma que o "turismo concorre, no processo de transformação dos territórios para o seu uso, com outros usos do território bem como com formações sócio-espaciais precedentes a seu aparecimento".

Neste sentido, a revitalização será aqui considerada como a restauração das formas físicas de locais degradados e gentrification como "parte de processos mais abrangentes de reestruturação espacial e da reorganização das classes rentistas" (SÁNCHEZ, 2010, p. 489).

Diante do exposto, pode-se compreender que os processos de intervenções urbanísticas nos centros históricos das cidades com objetivo de transformá-los em atrativos turísticos culturais através da valorização do patrimônio histórico e da dinâmica social destes lugares, gera uma série de conflitos entre os usos já existentes e os novos usos, conflitos estes que são relevantes para discussões em nível governamental, científico e comunitário acerca dos problemas urbanos e a sua relação com o desenvolvimento do turismo nas áreas centrais e a valorização social, econômica e cultural de espaços urbanos reabilitados.

\section{PRODETUR-NE E A REVALORIZAÇÃO DOS CENTROS HISTÓRICOS PARA/ PELO TURISMO}

O turismo na região Nordeste, como vetor de desenvolvimento regional através de políticas de megaprojetos e do PRODETUR, baseava-se na potencialidade natural (clima e litoral) da região para o turismo. Se anteriormente, a natureza da região (sertão) era vista como a razão do subdesenvolvimento econômico e social, neste momento a natureza (litoral) passa a exercer um papel contrário ao anterior (CRUZ, 2002).

Das cinco regiões do Brasil, a região Nordeste apresenta algumas peculiaridades que devem ser levadas em consideração. A primeira é que boa parte dos habitantes da região está abaixo da linha de pobreza, uma vez que os indicadores sociais da região são também inferiores aos níveis nacionais (BRASIL, 2010). Em segundo lugar, a região tem passado por períodos de secas graves e constantes dificuldades por escassez de água. Associada a essas peculiaridades, pode-se ressaltar também uma perceptível 
deficiência nos equipamentos urbanos. Estes fatores suscitaram o interesse especial do governo brasileiro e instituições especializadas, a fim de buscar alternativas que gerassem o desenvolvimento econômico e social da região.

Desta forma, nos princípios da década de 1990, o Banco Nacional de Desenvolvimento Econômico e Social (BNDES) iniciou vários estudos, a fím de identificar e analisar atividades econômicas do Nordeste que apontassem vantagens comparativas em relação às outras regiões brasileiras (BRASIL, 2004). Neste estudo foram apontadas quatro potencialidades: os setores da agricultura, a produção têxtil, a mineração de pedras ornamentais e o turismo.

Nesse período a região Nordeste já despontava como destino turístico, com destaque para o estado da Bahia (BRASIL, 2004). Entretanto, o desenvolvimento do turismo na região encontrava-se em risco pela insuficiência em termos de infraestrutura de apoio, bem como no que tange ao aparato institucional e organizacional.

Assim, o turismo passa a ser considerado como uma alternativa para recuperar a economia regional e, consequentemente, promover o desenvolvimento socioeconômico da região Nordeste. Partindo desse pressuposto, foram elaborados alguns programas, como por exemplo, o PRODETUR/NE que tem como objetivo geral promover, de forma sistemática, o desenvolvimento do setor turístico da região Nordeste (BRASIL, 2004). Vale ressaltar que até o momento de criação do programa, a região não possuía um programa ou sequer uma política que fosse direcionada ao setor turístico.

O PRODETUR/NE, aprovado em 1994, foi financiado com recursos externos e internos, através de uma operação entre o Banco do Nordeste do Brasil - BNB e o Banco Interamericano do Desenvolvimento - BID (BRASIL, 2004). A partir deste contrato, que foi pioneiro por seu caráter de programa global de investimentos múltiplos, o PRODETUR/NE começou a financiar diversas obras em três eixos principais: a) projetos de desenvolvimento, estruturação e modernização das instituições públicas gestoras da atividade e capacitação de mão de obra; b) obras de infraestrutura básica e serviços públicos a partir de projetos direcionados a cinco setores: saneamento, administração de resíduos sólidos, proteção e recuperação ambiental, transporte (construção e melhoria de rodovias) e recuperação do patrimônio histórico e, melhoria e ampliação de 8 aeroportos localizados nas cidades de São Luís (estado de Maranhão), 
Fortaleza (Ceará), Natal (Rio Grande do Norte), Aracaju (Sergipe), Porto Seguro, Lençóis e Salvador (Bahia) e Recife (Pernambuco) (BRASIL, 2004).

O programa divide-se em duas fases: PRODETUR I e PRODETUR II, prevendo-se um investimento de mais de US\$ 1 bilhão em projetos que incrementem o setor turístico nos nove estados que constituem a região (BRASIL, 2004). A primeira fase do programa iniciou-se em 1996 e foi concluída em 2001, já a segunda fase teve início em 2003 e irá até 2014 (BRASIL, 2004; CRUZ, 2002).

Os projetos financiados na primeira fase do programa englobaram ações voltadas à infraestrutura de apoio, tais como a construção, ampliação e modernização de aeroportos, saneamento básico, transporte, preservação e proteção ambiental, desenvolvimento institucional dos órgãos públicos gestores do turismo e a recuperação do patrimônio artístico, histórico e cultural (BRASIL, 2004).

A cidade de Aracaju, acompanhando as oportunidades e incentivos do Governo Federal ao setor turístico enquanto uma das áreas prioritárias para o desenvolvimento econômico e social do país na década de 90 elege alguns de seus espaços urbanos para serem transformados através de processos de reestruturação e adequação através de políticas de desenvolvimento do turismo em Sergipe, entre estes espaços, o Centro Histórico e a Orla de Atalaia (SANTOS, 2010b).

No tocante ao PRODETUR I em Aracaju, foram destinados mais de $\mathrm{R} \$ 53$ milhões em projetos de reestruturação urbana para o turismo, entre elas: a ampliação e internacionalização do Aeroporto Santa Maria, ampliação da oferta de meios de hospedagem e projetos de recuperação do patrimônio histórico, entre esses, o Projeto de Revitalização do Centro Histórico, que será abordado nesse artigo, e dos Mercados Municipais de Aracaju (BRASIL, 2004).

Destarte, o PRODETUR/NE teve um papel importante no processo de recuperação e revalorização do patrimônio histórico, artístico e cultural nas capitais nordestinas para o uso turístico destes espaços. Entretanto, a inserção do uso turístico em determinados espaços, em especial o urbano, que já possui sua aparência moldada pela forma que seus espaços se organizam na oferta de sensações e práticas sociais e econômicas (HARVEY, 2002), o processo de turistificação de centros históricos pode encontrar uma série de implicações decorrentes do choque entre os novos e antigos usos dados a esses espaços. 


\section{INTERVENÇÕES URBANAS NO CENTRO HISTÓRICO DA CIDADE DE} ARACAJU

Os centros históricos fortalecem a noção de centralidade pela somatória das atividades neles desenvolvidas. No entanto, tal noção começa a enfraquecer em detrimento do surgimento de uma rede de subcentros ${ }^{3}$ decorrentes do processo de descentralização ocasionada pela expansão fragmentada do tecido urbano, denominada suburbanização (PAES, 2010).

No início dos anos 1970, a cidade de Aracaju vivenciava o seu período urbano de crescimento acelerado e na mesma época passa a sofrer o processo de descentralização com a crescente desvalorização de seu centro urbano enquanto espaço de lazer e moradia, ocasionando no seu esvaziamento e subutilização (LIMA, 2009).

A falta de investimentos públicos e privados nas áreas centrais acaba por transformá-las em espaços degradados, marginalizados e subutilizados. No caso aracajuano, equipamentos urbanos, a exemplo de seus mercados (Mercado Antônio Franco e Mercado Thales Ferraz) localizados no Centro Histórico, começam a dar sinais de degradação e adensamento, atraindo cada vez mais um maior número de barracas, lojas populares e o comércio informal. Esta situação era semelhante em outros espaços do centro e perdurou durante a década de 1980, quando a cidade ganhava as suas feições metropolitanas (LIMA, 2009).

Assim, o centro da cidade de Aracaju passa a perder sua atratividade para o lazer, para moradia e para o comércio de luxo. Entretanto, a perda das classes abastadas e a migração do comércio do centro para outras centralidades da cidade, principalmente para a zona sul, não diminuiu as atividades comerciais neste espaço (LIMA, 2009).

Entretanto, a intensificação dos fluxos de pessoas, da poluição sonora, visual e ambiental decorrentes do intenso comércio formal e informal na área colaborou para a decadência e degradação do centro enquanto espaço de lazer e de representação da cultura e da história do aracajuano.

\footnotetext{
${ }^{3}$ Aqui os subcentros serão tratados como espaços periféricos dotados de infraestrutura de equipamentos e serviços similares, entretanto mais modernos, aos do centro urbano, que surgem através da necessidade que a cidade tem de se expandir para atender o crescente número de habitantes, bem como as novas necessidades causadas pelas mudanças de paradigmas socioambientais atreladas aos avanços tecnológicos e científicos que vem alterando o modo das relações interpessoais e das relações entre o homem e o meio ambiente urbano.
} 
A situação contemporânea dos espaços centrais os torna objetos de preocupação desde os anos 1950 na Europa e América do Norte e mais tarde no Brasil, de modo mais intenso, após os anos 80 (VARGAS; CASTILHO, 2009), quando algumas cidades brasileiras detentoras de um grande acervo de monumentos arquitetônicos e urbanísticos que remontam seu passado adotam processos de intervenções urbanas defendidas pelo setor público (PAES, 2010).

Além da preservação e restauração física do patrimônio cultural, a adequação destes espaços para a realização de práticas de lazer e turismo (LEITE, 2007) também tem como objetivo o (re) desenvolvimento e a (re) apropriação destes lugares pelo capital financeiro e cultural.

Muitas cidades, a exemplo de Recife, Salvador, Rio de Janeiro e Barcelona, adotaram projetos urbanos de reabilitação com objetivo de valorizar determinados espaços para o setor de serviços, dentre estes o mercado de turismo, lazer e eventos em espaços nostálgicos.

Diante da situação de degradação do centro urbano de Aracaju e da necessidade de inserção da cidade na rota do turismo do Nordeste, a fim de torná-la capaz de competir com as demais capitais nordestinas, foram adotados alguns projetos para a revitalização do seu Centro Histórico através dos incentivos financeiros do PRODETUR I. Dentre os projetos adotados, dois chamam a atenção em termos de amplitude e resultados obtidos. O primeiro projeto foi desenvolvido sob a responsabilidade da gestão do Governo Estadual e teve como foco a transformação completa dos antigos mercados, Mercado Antônio Franco e Mercado Thales Ferraz. Já o segundo projeto visava a revitalização do núcleo urbano original da cidade (ruas e praças) e ficou a cargo da Prefeitura Municipal. Estes projetos tinham como objetivo tornar este ambiente propício à realização de atividades voltadas ao mercado de turismo e lazer.

No que concerne ao projeto de revitalização do núcleo urbano original é importante ressaltar que teve como objetivo a reabilitação do patrimônio arquitetônico e histórico como forma de fortalecer as atividades comerciais tradicionais no local. Ademais, objetivava impulsionar o turismo através do resgate da relação histórica entre o centro e o rio Sergipe, tendo em vista que a cidade de Aracaju está situada na margem deste rio. 
Este projeto delimitou três setores especiais de turismo, promovendo a revitalização de edificações antigas, das praças e da ponte do Imperador, a construção de pórticos com informações acerca dos monumentos históricos, a sinalização das ruas e a melhora e ampliação dos equipamentos coletivos, como por exemplo, telefones e assentos públicos (SANTOS, 2005).

Estas intervenções influenciaram no novo perfil paisagístico do centro histórico. Porém, é importante ressaltar que não conseguiram impor uma "nova" identidade, uma vez que não eliminaram seus usos anteriores, seja no que se refere à comercialização informal, atividade que sempre atuou como um ponto identitário para a área, ou nos territórios de prostituição que parecem já estar consolidados neste espaço central.

Além disso, algumas dessas intervenções, a exemplo da construção dos pórticos com as informações acerca dos monumentos e sinalização não perduraram, sendo retirados posteriormente. Atualmente, a Prefeitura Municipal em parceria com o Governo Estadual está executando o projeto de sinalização turística, a fim de facilitar o deslocamento de visitantes e população local no Centro Histórico.

O outro projeto citado anteriormente teve como objetivo a restauração dos mercados Antônio Franco e Thales Ferraz e a ampliação do Mercado Municipal de Aracaju através da construção do Mercado Antonio Franco a partir da reciclagem dos antigos moinhos de Sergipe e do armazém de trigo ${ }^{4}$ (Figura 1).

\footnotetext{
${ }^{4}$ ANA LIBÓRIO E GÂNDARA JR. ARQUITETOS ASSOCIADOS. Projeto de Resgate da Paisagem Urbana dos Mercados Municipais de Aracaju. Disponível em: $<\mathrm{http}: / /$ analiborioarquitetos.com.br/category/portfolio/mercado-antonio-franco-e-thales-ferraz/>. Acesso em: 19/03/2012.
} 


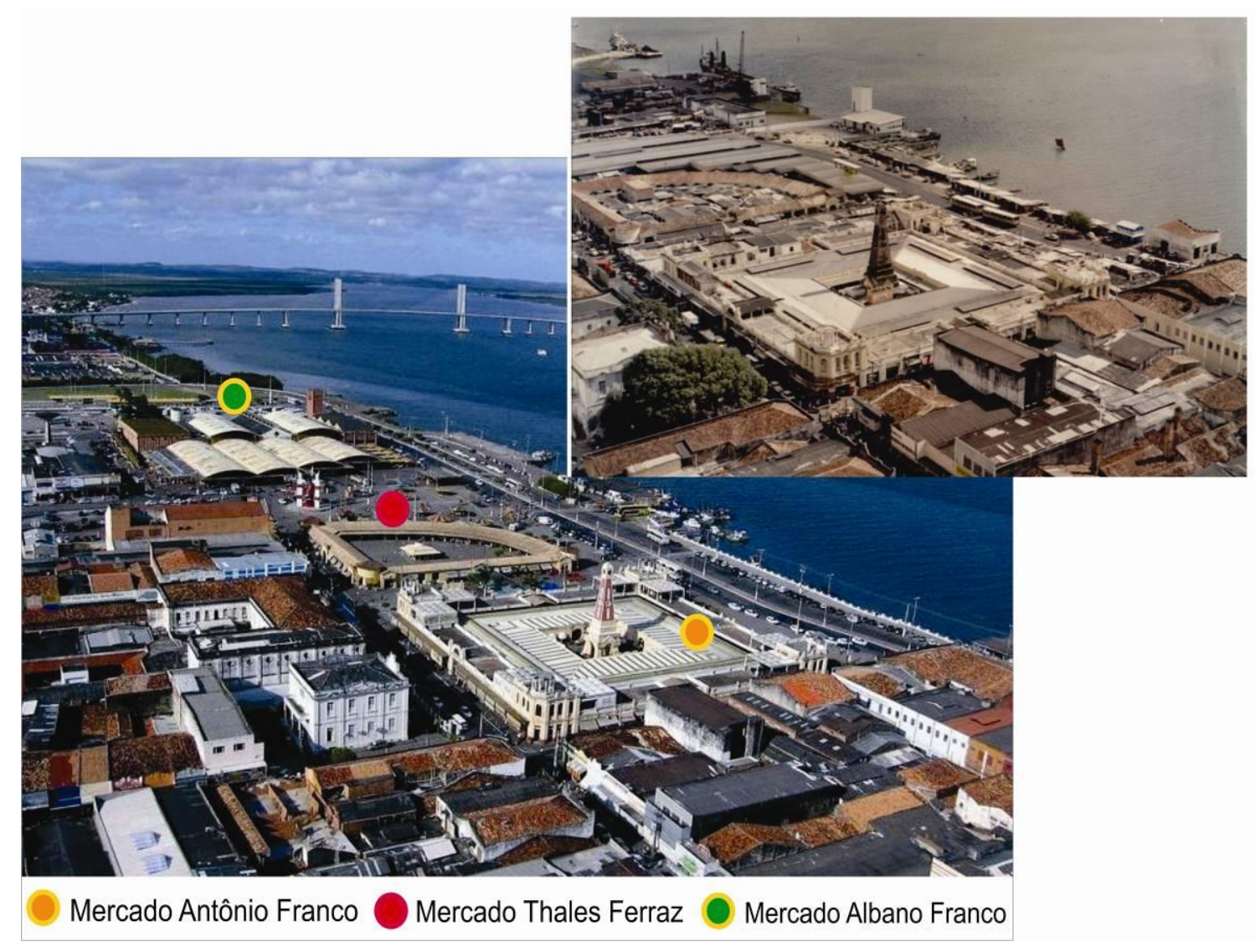

FIGURA 1 - O ANTES E O DEPOIS DOS MERCADOS MUNICIPAIS DE ARACAJU FONTE: ADAPTAÇÃO DE RAFAELLE PINHEIRO, 2011.

As principais intervenções resultantes deste projeto foram:

- Restauração das edificações do mercado, reestabelecendo suas condições sanitárias e a capacidade de uso;

- Reorganização da comercialização de hortifrutigranjeiros, confecções e artesanatos no interior das edificações;

- Criação de um novo mercado através da reciclagem do antigo moinho de Sergipe e do armazém de trigo;

- Criação de áreas de carga e descarga;

- Recuperação do sítio urbano degradado;

- Estacionamento para caminhões e carroças.

A ideia contida no projeto partia do princípio da dinamização da prática turística na cidade de Aracaju. A fim de alcançar este objetivo, o projeto considerava algumas proposições para a área de turismo e lazer:

- Construção de restaurantes panorâmicos; 
- Preservação da memória arquitetônica;

- Higienização;

- Construção de uma praça para realização de eventos;

- Construção de uma área específica para comercialização de artesanatos.

Estes mercados funcionavam com bastante precariedade, pois apresentavam problemas sanitários gravíssimos, além de não haver controle dos produtos comercializados. De fato, havia uma grande comercialização informal que incluía desde os vendedores ambulantes até os comerciantes de produtos eletrônicos e muitos destes foram excluídos a partir da nova forma de organização do mercado (Figura 2).

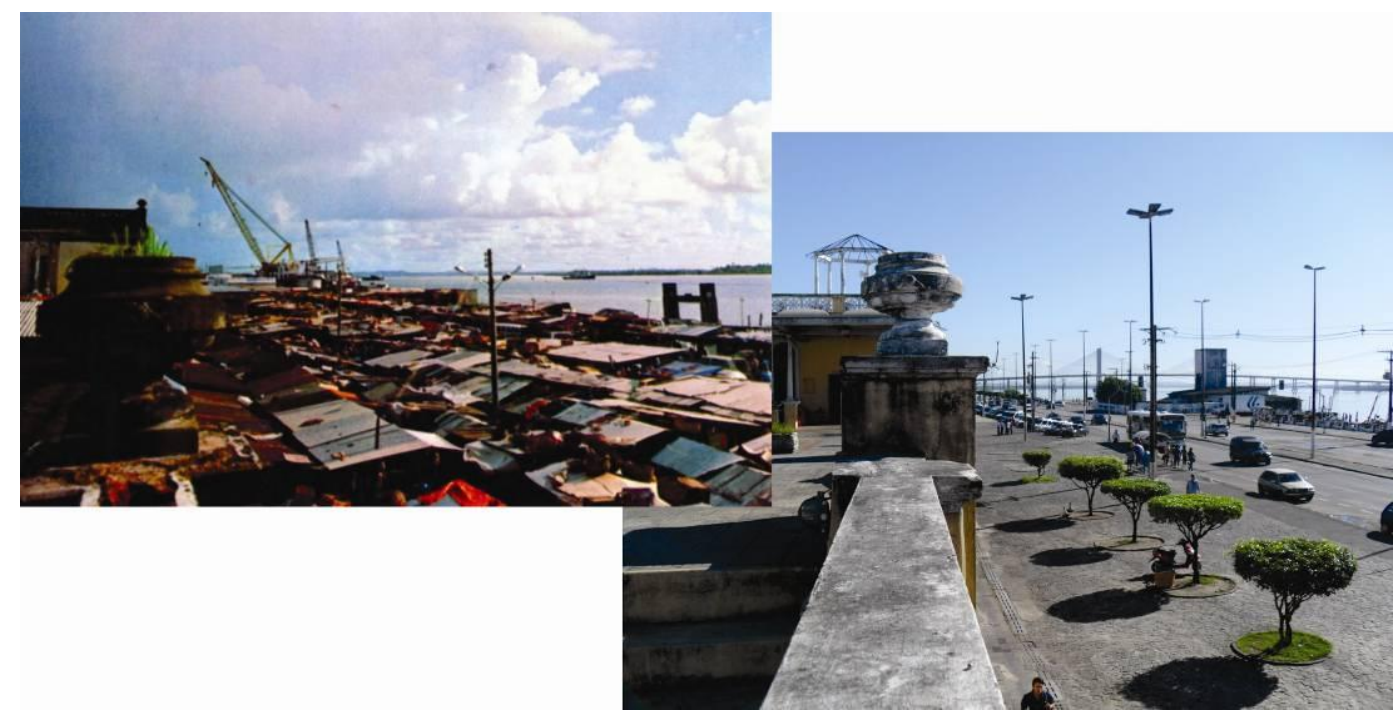

FIGURA 2 - O ANTES E O DEPOIS DO MERCADO ANTÔNIO FRANCO FONTE: RAFAELLE PINHEIRO, 2011.

Apesar do total de investimento proveniente do PRODETUR/NE, algumas materialidades resistiram às ações transformadoras dos mercados municipais, uma vez que ainda permanecem os problemas com o odor e com o armazenamento dos produtos comercializados, sobretudo, com os pescados e carnes. Ademais dos problemas sociais, como por exemplo, a prostituição que caracteriza o mercado e a marginalidade.

Entretanto, o resultado deste projeto no Centro Histórico é mais do que uma intervenção arquitetônica, uma vez que este espaço se transformou em um espaço de consumo simbólico e econômico direcionado a atividade turística, já que se percebe o incremento do fluxo turístico nesse espaço. 
Ao longo das últimas décadas foram desenvolvidos e ainda estão em andamento projetos de revitalização de prédios e monumentos arquitetônicos, bem como de espaços destinados ao lazer e turismo, tais como praças e pontos turísticos, a exemplo das praças Olímpio Campos, Fausto Cardoso, Teófilo Dantas e Almirante Barroso e da Ponte do Imperador. A cidade de Aracaju vem promovendo a revitalização e refuncionalização de vários prédios e espaços de lazer do seu Centro através de parcerias com o setor privado ou aproveitando-se de programas de âmbito nacional ou internacional.

Dentre as iniciativas implantadas, tem-se a restauração e transformação do Palácio Olímpio Campos em Palácio Museu. De arquitetura no estilo eclético europeu com influência neoclássica e mantido com recursos do estado, este equipamento de lazer gratuito oferece visitas guiadas com o objetivo transmitir para o visitante a história política do Estado de Sergipe ${ }^{5}$.

O antigo prédio do colégio Atheneuzinho, através da parceria público-privada, também foi revitalizado e atualmente abriga o Museu da Gente Sergipana. ${ }^{6}$ Este equipamento, também gratuito, tem como finalidade proporcionar aos visitantes, de forma interativa e utilizando de recursos tecnológicos, experiências culturais através do conhecimento das peculiaridades do povo sergipano.

Outras intervenções que merecem destaque pelo seu direcionamento para a atividade turística são: a restauração do prédio antigo do Centro de Turismo (antiga Escola Normal) em 2002 e a reabertura da Rua do Turista (antiga Rua 24h) em $2011^{7}$.

Algumas intervenções ainda se encontram em andamento, como a construção de um Centro Cultural, a partir da restauração do prédio da antiga Alfândega e a reforma do antigo restaurante Cacique Chá com a restauração dos painéis do artista sergipano Jenner Augusto presentes no local. ${ }^{8}$ Outras iniciativas condizem com o uso de alguns espaços para a realização de eventos culturais, como o Forró Caju na Praça Hilton

\footnotetext{
PALÁCIO MUSEU OLÍMPIO CAMPOS. O Palácio. Disponível em: <http://www.palacioolimpiocampos.se.gov.br>. Acesso em: 18/03/2012.

6 MUSEU DA GENTE SERGIPANA. Disponível em: <http://www.museudagentesergipana.com.br>. Acesso em: 18/03/2012.

${ }^{7}$ Informações obtidas através das observações realizadas durante a pesquisa de campo durante o mês de dezembro de 2011.

${ }^{8}$ Idem.
} 
Lopez (anual) e a Rua da Cultural no espaço entre os mercados Thales Ferraz e Antônio Franco (semanalmente).

Desde o ano de 2009, a cidade de Aracaju, junto com as cidades de São Cristóvão e Laranjeiras, estão incluídas no PAC Cidades Históricas, o programa, de abrangência nacional, que tem como objetivo a integração do patrimônio às políticas de desenvolvimento econômico e regional, com ênfase no turismo ${ }^{9}$. Aracaju, com previsão de um repasse de $\mathrm{R} \$ 100$ milhões, aplicará os recursos na recuperação e promoção do seu patrimônio arquitetônico ${ }^{10}$.

Levando-se em consideração a valorização dos centros históricos enquanto espaços eleitos para o consumo de bens e serviços vinculados ao lazer e turismo e a sua consequente refuncionalização para os fins do mercado de capitais, tem-se o Centro Histórico de Aracaju enquanto um espaço requalificado para o turismo e lazer através das intervenções promovidas pelos projetos de revitalização de pontos específicos desta malha urbana da capital.

O papel do turismo nos Centros Históricos, seguindo os princípios do turismo cultural, é o de promover e valorizar o patrimônio em concomitante a sua utilização (BRASIL, 2008). A revitalização e turistificação desses espaços favorecem uma política de city marketing ${ }^{11}$ adotada por muitas cidades no mundo, uma vez que os centros históricos não devem ser entendidos apenas como um patrimônio, mas como um espaço pertencente de forma particular a outros setores sociais que cristalizam valores locais e globais da sociedade e do mundo do turismo (SANTOS; CAMPOS, 2010).

O Projeto de Revitalização do Centro Histórico e dos Mercados Municipais de Aracaju, através da recuperação do patrimônio artístico, histórico e cultural, objetivava a eleição e transformação dos espaços eleitos em produtos capazes de diversificar e ampliar a oferta turística da cidade a partir do segmento de turismo cultural. Ao analisar a ação do PRODETUR no Nordeste, Cruz (2002, p. 144-145) corrobora com esta ideia ao afirmar que "diversificar o produto turístico do litoral nordestino pelo chamado

\footnotetext{
${ }^{9}$ BRASIL, Ministério da Cultura. Instituto do Patrimônio Histórico e Artístico Cultural. Programa de Aceleração do Desenvolvimento - Cidades Históricas. Disponível em: <http://portal.iphan.gov.br/baixaFcdAnexo.do?id=1332>. Acesso em: 18/03/2012.

10 INFONET. PAC Cidades Históricas prevê investimentos de R\$ 230 milhões em Sergipe. Disponível em: <http://www.infonet.com.br/cultura/ler.asp?id=100017\&titulo=cultura>. Acesso em: 18/03/2012.

${ }^{11}$ Para um maior aprofundamento na discussão sobre city marketing ver GARCIA, F. E. S. Cidade espetáculo. Política, planejamento e city marketing. Curitiba: Ed. Palavra, 1997.
} 
turismo cultural, em contraposição ao turismo de sol e praia, é uma das motivações desses empreendimentos de revitalização de centros históricos nas capitais nordestinas".

Atualmente, o Centro Histórico está envolvido no discurso de uma nova imagem da cidade de Aracaju. Zukin (2000), em seu artigo que trata das paisagens pósmodernas, enfatiza a existência das "paisagens de poder", o que se pode relacionar com o processo de revitalização do Centro Histórico e do Mercado Central de Aracaju, já que representa uma forma estratégica de apropriação cultural de um lugar histórico e sua posterior transformação em um segmento do mercado de bens simbólicos, em que há uma convergência prática e simbólica de uma representação de cidade moderna.

O impacto desses projetos de intervenção sobre o espaço mostra que por mais que os objetivos dos governos locais (municipal e estadual) tenham sido alcançados a partir da melhoria da infraestrutura dando suporte ao mercado turístico, as consequências sociais são expressivas, uma vez que os sujeitos envolvidos são variados e os interesses econômicos distintos.

\section{CONSIDERAÇÕES FINAIS}

De acordo com as discussões teóricas acerca da relação entre turismo, patrimônio, cultura e urbanidade no viés da inserção de novas funcionalidades aos espaços centrais, tendo como caso o Centro Histórico da cidade de Aracaju, percebe-se o valor de uso do patrimônio cultural das cidades não só para a atividade turística, mas também para a propagação de uma imagem positiva das cidades em relação à força cultural e ao sentimento de pertencimento a uma cultura e história tida como "comum" a todos os seus habitantes.

Entender os processos de intervenções urbanas para a valorização do patrimônio histórico e cultural exige o estudo dos conflitos gerados entre os novos e antigos usos, bem como a relação entre os usuários e o espaço. Ainda que os processos de revitalização e reabilitação das áreas centrais, marginalizadas e degradadas em termos físicos e sociais a partir do processo de expansão e descentralização urbana, tenham como objetivo lhes impor novos valores e usos na construção de uma imagem positiva, é necessário que os projetos ultrapassem os aspectos físicos e (re) ativem o sentimento 
de pertencimento e a valorização cultural, histórica, social e econômica dos Centros urbanos.

No caso específico das intervenções urbanas empreendidas no Centro Histórico de Aracaju, através da revitalização promovida pelo PRODETUR I, foi possível detectar a grande influência do turismo e como a atividade passou a ser inserida nesta área. De fato, é a partir dessa apropriação que a capital começa a oferecer o Centro Histórico enquanto um dos seus maiores atrativos culturais através da realização de roteiros turísticos dentro da cidade - city tours - que englobam/agregam outros atrativos já consolidados, a exemplo da orla da praia de Atalaia.

Neste processo, o turismo concorre com o intenso uso comercial da área que acaba poluindo sonora e visualmente o ambiente, além de concorrer com outros usos ilegais e marginalizados socialmente, como a prostituição, moradores de rua, comércio de entorpecentes e usuários de drogas ilícitas que circulam e se apropriam do espaço ao longo do dia e com mais intensidade durante à noite.

A cidade ainda vem adequando equipamentos e áreas do seu centro para o turismo, e é neste processo contínuo de revitalização para a gentrificação que este espaço recebe novas funções através de ações sociais que lhe confere uma nova imagem no que tange as seus aspectos físicos e simbólicos.

\section{REFERÊNCIAS}

BERTONCELLO. R. Turismo y património, entre la cultura y el negocio. In: PAES, M. T. D.; OLIVEIRA, M. R. S. (Orgs.). Geografia, Turismo e Patrimônio Cultural. São Paulo: Annablume, 2010. p. 33-53.

BRASIL. Tribunal de Contas da União - TCU. Avaliação do TCU sobre o Programa Desenvolvimento do Turismo no Nordeste. Brasília: TCU, Secretária de Fiscalização e Aplicação de Programas de Governo, 2004.

Ministério do Turismo. Turismo Cultural: orientações básicas. 2. ed. Brasília: Ministério do Turismo, 2008.

IBGE, Censo Demográfico, 2010. Disponível em:

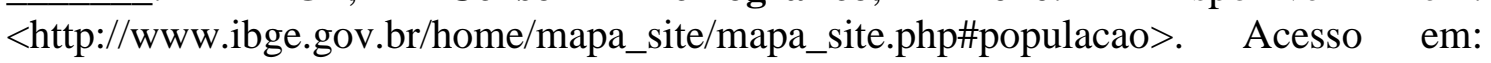
09/03/12. 
CONCEIÇÃO, G. A.; BRITO, G. M.; SANTOS, M. G. R.; PINHEIRO, R. C. S.; PAIXÃO, S. M. P. Centro Histórico de Aracaju: urbanismo, identidade, usos, políticas urbanas e turismo. In: ENCONTRO NACIONAL DE TURISMO COM BASE LOCAL, 11, 2010, Niterói. Anais do XI Encontro Nacional de Turismo com Base Local. Niterói: UFF, 2010. p. 2073-2088.

CRUZ, R. C. Política de Turismo e Território. 3. ed. São Paulo: Contexto, 2002.

HARVEY, D. A condição pós-moderna. 15. ed. São Paulo: Edições Loyola, 2002.

LEITE, R. P. Contra-usos da Cidade: lugares e espaço público na experiência urbana contemporânea. 2. ed. Campinas, SP: Editora da UNICAMP; Aracaju, SE: Editora UFS, 2007.

LIMA, E. F. Etnografias do Cotidiano: "revitalização" e (re) invenção do Centro Histórico de Aracaju. In: CONGRESSO BRASILEIRO DE SOCIOLOGIA, 14, 2009, Rio de Janeiro. Anais do XIV Congresso Brasileiro de Sociologia. Rio de Janeiro: Sociedade Brasileira de Sociologia, 2009. p. 1-25.

LUCHIARI, M. T. D. P. Urbanização turística: um novo nexo entre o lugar e o mundo. In: LIMA, L. C. (Org.). Da cidade ao campo: a diversidade do saber-fazer turístico. Fortaleza: UECE, 1998. p. 15-29.

PAES, M. T. D. Introdução e Apresentação. In: PAES, M. T. D.; OLIVEIRA, M. R. S. (Orgs.). Geografia, Turismo e Patrimônio Cultural. São Paulo: Annablume, 2010. p. 13-32.

SÁNCHEZ, F. A reinvenção das cidades para um mercado mundial. 2. ed. Chapecó, SC: Argos, 2010.

SANTOS, C. A. J. Fundamentos Geográficos do Turismo. São Cristóvão: CESAD/UFS, 2010a.

Impactos territoriais do turismo na cidade de Aracaju - Sergipe. In: ENCONTRO NACIONAL DE TURISMO COM BASE LOCAL, 11, 2010, Niterói. Anais do XI Encontro Nacional de Turismo com Base Local. Niterói: UFF, 2010b. p. $558-575$

Turismo en Aracaju: el papel del programa de desarrollo del turismo en nordeste de Brasil. In: SEMINARIO DE LA APEC, 10, 2005, Barcelona. Actas del X Seminario de la APEC. Barcelona: APEC, 2005. p. 89-96.

SANTOS, C. A. J.; CAMPOS, A. C. Turismo, cidade e patrimônio: um breve olhar sobre os centros históricos de São Cristóvão e Laranjeiras. In: ENCONTRO NACIONAL DE TURISMO COM BASE LOCAL, 11., 2010, Niterói. Anais do XI Encontro Nacional de Turismo com Base Local. Niterói: UFF, 2010. p. 1856-1875. 
SOTRATTI, M. A. A requalificação urbana e a mercantilização do patrimônio cultural: o caso do Centro Histórico de Salvador - Pelourinho. In: PAES, M. T. D.; OLIVEIRA, M. R. S. (Orgs.). Geografia, Turismo e Patrimônio Cultural. São Paulo: Annablume, 2010. p. 139-154.

THE NEW YORK TIMES. Após 30 anos, reforma da Times Square será concluída: revitalização de ponto histórico da cidade fez criminalidade diminuir e atraiu empresas e turistas. 10/11/2010. Disponível em: <http://ultimosegundo.ig.com.br/mundo/nyt>. Acesso em: 04/04/2011.

VARGAS, H. C.; CASTILHO, A. L. H. Intervenções em centros urbanos: objetivos, estratégias e resultados. In: VARGAS, H. C.; CASTILHO, A. L. H (Orgs.) Intervenções em centros urbanos: objetivos, estratégias e resultados. 2. ed. Barueri, SP: Manole, 2009. p. 1-51.

ZUKIN, S. Paisagens urbanas pós-modernas: mapeando cultura e poder. In: ARANTES, A. (Org.). O Espaço da Diferença. Campinas: Papirus, 2000. p. 80-103.

Recebido em: 30-12-2011.

Aprovado em: 30-01-2012. 